\title{
Indirect approaches for estimating the efficiency of the cold metal transfer welding process
}

\author{
Bachir Mezraga ${ }^{a}$, Frédéric Deschaux Beaume ${ }^{a}$, Sebastien Rouquette (i] ${ }^{a}$ and Mustapha Benachour (i] ${ }^{b}$

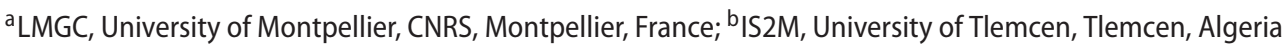

\begin{abstract}
In this work, two indirect approaches are compared to estimate the efficiency of the cold metal transfer welding process with two different current waveforms. The first approach is based on an analytical heat transfer model coupled with thermocouple measurements. The second method includes numerical heat transfer simulation of aluminium filler on the galvanised steel sheet. Then a diffusional-growth model allows evaluating the thickness of the Fe-Al intermetallic layer that was compared it to that of the experimental one. Results show that both methods give very similar process efficiencies. The process efficiency reaches a high value $(0.92)$ with current waveforms using high-intensity pulses of short duration, whereas it decreases to 0.78 with current waveforms using low-intensity pulses of long duration.
\end{abstract}

\author{
KEYWORDS \\ Cold metal transfer; welding; \\ process efficiency; \\ modelling; thermal cycle; \\ intermetallic layer; current \\ waveform
}

\section{Introduction}

The weld microstructure and associated mechanical properties depend directly on the welding heat input that controls the solidification behaviour, as demonstrated by David and Vitek [1] and Liu et al. [2]. Therefore, an accurate prediction of the heat input transmitted to the base metal is required to ensure assemblies of a good quality. In arc welding processes, the heat transferred to the workpiece is expressed as a linear energy $E\left(\mathrm{~J} \mathrm{~mm}^{-1}\right)$ calculated from the ratio of the power to the welding speed $V \cdot I / S$ where $V$ : the voltage (V), $I$ : the welding current (A) and $S$ : the travel speed $\left(\mathrm{mm} \mathrm{s}^{-1}\right)$. Radaj [3] reported that a part of this energy is lost by radiation and convection in the surrounding gas, conduction in the welding torch and/or by metal vaporisation. The fraction of transmitted energy is called process efficiency $\eta$. It is defined as the ratio of the energy transferred to the workpiece to the total energy generated by the welding process. The knowledge of this process efficiency is useful information for either analytical models or/and numerical heat transfer models. However, its determination remains a delicate challenge due to the complexity of physical mechanisms responsible for heat transfer in arc welding. Its value depends on many factors such as the welding process, the assembly geometry and welding parameters. Dupont and Marder [4] compared, using a Seebeck arc welding calorimeter, the process efficiency of various welding processes. They obtained values varying from about 0.5 (for the gas tungsten arc welding (GTAW) process) to more than 0.8 (for the gas metal arc welding (GMAW) process). Niles and Jackson [5] explained the low efficiencyof the GTAW process by the heat loss by conduction in the tungsten-based electrode. Many authors measured different efficiency values for the GTAW process. Orlowicz and Trytek [6] found it about 0.7, whereas Collings et al. [7] measured values around $0.77-0.9$ with regard to arc current. Giedt et al. [8] reported an average value of 0.8. In a recent review, Stenbacka et al. [9] explained that these variations were probably due to differences in experimental methods, welding parameters or materials and proposed an average efficiency value of 0.78 .

In the GMAW process, the fusible electrode filler is fed through a welding torch with a regular speed. Owing to the fusion of the electrode, the physical mechanisms of the heat transfer to the workpiece are more complex. The process efficiency is quite different according to the welding conditions. For high welding current, it is generally accepted that the metal heating is mainly due to the condensation heat of electrons on the metal surface. As explained by Lesnewich [10], these electrons emitted by the cathode, which is generally the workpiece on the GMAW process, accelerate while travelling through the arc. Then they deliver their kinetic energy as condensation heat to the anode, corresponding to the filler wire, producing its end melting. The molten filler is transferred as droplets to the workpiece leading to heat and mass exchanges. Unfortunately, a fraction of heat is lost due to the metal vaporisation. Waszink and Van Den Heuvel [11] have shown that the resistive heating of the filler wire also contributed, to some extent, to the heating, especially with low welding current. They explained in this case 
that the heating is too low to produce the droplet detachment before the filler wire enters in contact with the workpiece, generating periodically short circuits and arc extinction. Heat efficiency values are different according to the welding current range and metal transfer mode. Dupont and Marder [4] measured heat efficiencies between 0.8 and 0.9 for GMAW and noticed a slight decrease with an increase in the welding current. Bosworth [12] observed the process efficiency higher than 0.95 during 'short-circuit mode' with low welding current. The process efficiency seems lower in the pulsed metal transfer mode, as indicated by Joseph et al. [13]. They used a liquid nitrogen calorimeter for the measurements and recorded an efficiency of about 0.7.

The cold metal transfer (CMT) process is derived from GMAW allowing an electronic control metal transfer (short circuit mode). The CMT was initially developed for minimising the welding heat input, as observed by Pickin et al. [14]. This process couples an alternating feeding of the filler wire to get a precise control of the electrical current waveforms that allows a deposition of the filler metal with a minimal heat input, as described by Mezrag et al. [15]. Owing to the specific metal transfer mode of this process, the physical mechanisms controlling the heat transfer are different from those of the GMAW process. Recently, Pépe et al. [16] conducted a comparative study of process efficiencies of several controlled transfer GMAW processes, using both insulated box calorimeter and liquid nitrogen calorimeter. They measured a CMT heat efficiency of 0.88 using a liquid nitrogen calorimeter and 0.81 using an insulated box calorimeter. This is in good agreement with result of Egerland and Colegrove [17] who reported a CMT heat efficiency of 0.8 measured with an insulated box calorimeter.

The disadvantage of calorimetric methods is that they neglect heat losses between the beginning of the welding and the beginning of the calorimetric measurement, as explained by Malin and Sciammarella [18] and Pépe et al. [16]. Stenbacka et al. [9] found that these uncontrolled heat losses in the surrounding gas or in the clamping device of the sample cause an underestimation and can reach $30 \%$ of the heat efficiency of the process. An alternative method consists in measuring, using thermocouples, the thermal cycle in one point of the workpiece near the welding zone, and in using analytical or numerical models to identify the heat efficiency. Using this method, Colegrove et al. [19] estimated an average CMT efficiency of 0.9 . The validity of this indirect approach relies strongly on the proposed physical model. It depends on the heat source model, boundary conditions and the quality of the thermal measurements. The accuracy of the thermocouple localisation and the thermal contact with the workpiece also strongly affect the measured temperature.

In light of previous studies, the objective of the present study is to estimate the CMT heat efficiencies with two indirect approaches during the deposition of aluminium to try overcome the uncertainty of calorimetry measurements and simulation estimation cited above. These experiments will also bring an insight into the relationship between the current waveform of CMT welding and the heat transferred in the workpiece.

\section{Experimental details}

Two indirect methods are compared to study the heat transferred to a metal plate using the CMT welding process with various welding parameters. Both are based on the deposition of $200 \mathrm{~mm} \mathrm{Al}-\mathrm{Si}_{5}$ weld bead on the middle of a $1 \mathrm{~mm}$ thick low-carbon DC01 galvanised steel plate of dimensions $250 \mathrm{~mm} \times 100 \mathrm{~mm}$. This configuration facilitates temperature measurements on the plate. Indeed, the steel plate remains in a solid state during all the welding as the melting temperature of aluminium is much lower. Both Cao et al. [20] and Lin et al. [21] proved that the $\mathrm{Zn}$ coating promotes aluminium wetting on the steel surface. As a consequence, the heat transfers into the steel plate as it happens during a real welding operation. Without this coating, the aluminium deposit does not spread onto the steel surface as observed by Peyre [22] and then the heat transfer can be different due to a higher heat exchange of the aluminium deposit with the surrounding gas. The steel plate is clamped on its four corners to limit the heat exchange with the support. The electrical parameters are recorded and synchronised (Figure 1(a)) for all the tests, as detailed in our previous study [15], in order to calculate the average power.

The first method is based on the measurement of the welding thermal cycle with thermocouples located near the steel/aluminium interface (Figure 1(b)). As the steel surface remains in a solid state, the thermocouples can be accurately positioned on the steel plate at $0.2 \mathrm{~mm}$ from the interface where the aluminium is deposited. For each sample, two type K thermocouples with a diameter of $0.5 \mathrm{~mm}$ are located on steel plate back into drilled-holes of the same diameter and a depth of $0.8 \mathrm{~mm}$. They are positioned along the centreline with a distance of $20 \mathrm{~mm}$ from each other. Holes are filled with thermal paste which is a substance that increases the thermal conductivity between the surfaces of the plate and thermocouples, achieving a heat seal when these surfaces are not perfectly connected.

The second method is based on the high reactivity between liquid aluminium and steel that forms $\mathrm{Fe}-\mathrm{Al}$ intermetallic compounds (IMC) between steel and aluminium. The thickness of the IMC layer is directly correlated to the thermal cycle at the $\mathrm{Al} /$ steel interface. This IMC layer thickness can be used to estimate the amount of heat transferred to the steel plate leading to the process efficiency. The IMC layer thickness is 


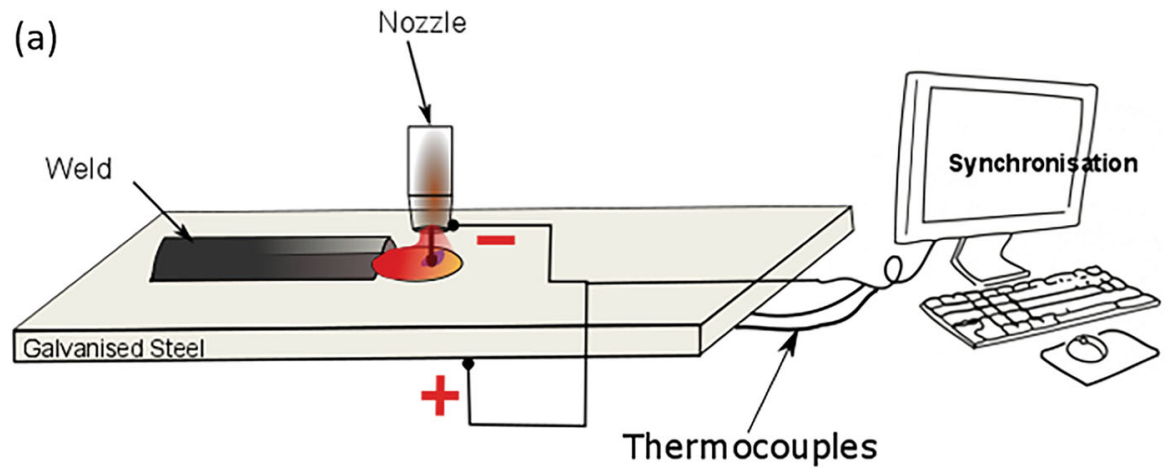

(b)

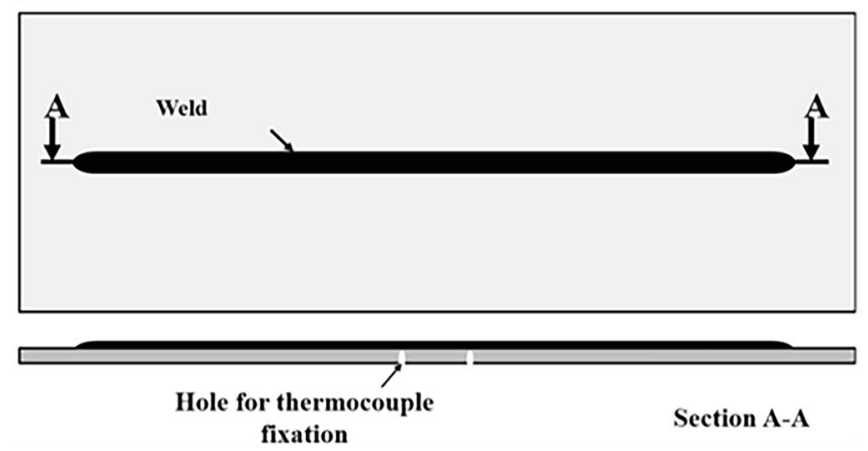

Figure 1. (a) Experimental set-up scheme, (b) weld a thermocouples location.

Table 1. Process parameters selected for welding tests.

\begin{tabular}{|c|c|c|c|c|c|c|}
\hline Test No & Waveform type & $\begin{array}{l}\text { Fronius wire feeding } \\
\qquad\left(\mathrm{m} \mathrm{min}^{-1}\right)\end{array}$ & $\begin{array}{l}\text { Pulse current } \\
\text { (A) }\end{array}$ & Pulse time (ms) & Wait current (A) & $\begin{array}{c}\text { Average power } \\
\left(\mathrm{J} \mathrm{s}^{-1}\right)\end{array}$ \\
\hline 1 & 1 & 1.8 & 47.1 & 13 & 16.4 & 477 \\
\hline 2 & 1 & 1.9 & 64.3 & 11 & 17.8 & 570 \\
\hline 3 & 1 & 2 & 81.4 & 9 & 19.2 & 786 \\
\hline 4 & 1 & 2.1 & 98.5 & 7 & 20.7 & 755 \\
\hline 5 & 2 & 2.8 & 150 & 1.30 & 32.6 & 463 \\
\hline 6 & 2 & 3.1 & 150 & 1.38 & 34.6 & 505 \\
\hline 7 & 2 & 3.2 & 150 & 1.53 & 38.4 & 523 \\
\hline
\end{tabular}

measured with an optical microscope for each sample for three polished cross-sections of the weld bead.

Seven sets of CMT welding parameters are chosen to investigate the effect of process parameters on the process efficiency. Table 1 groups the process parameters measured for each welding set. Figure 2 illustrates the current and voltage waveforms as well as the mechanism of metal transfer characteristic of the CMT process. The current pulse (pulse phase) produces a highenergy electrical arc allowing the melting of the filler wire tip. Then, the feeding of the filler metal is done during the 'wait phase' under a low arc current. Finally, the filler wire reaches the steel plate surface causing a short circuit and arc extinction, then the wire moves back until breaking of liquid bridge between weld pool and wire followed of arc re-ignition the arc and the cycle restart. Two kinds of current waveforms are chosen in this study. The first one consists of long pulses with low current (tests 1 to 4 , Table 1 ), producing the transfer of large droplets of molten metal at low frequency, while the second one consists of short pulses with high current (tests 5 to 7 , Table 1), producing the transfer of small droplets at high frequency. The filler wire diameter $(1.2 \mathrm{~mm})$, the welding speed $\left(60 \mathrm{~cm} \mathrm{~min}^{-1}\right)$, the argon gas flow rate $\left(12 \mathrm{~L} \mathrm{~min}^{-1}\right)$ and the nozzle-toplate distance $(10 \mathrm{~mm})$ are kept constant for all tests. Two welds are made for each welding condition in order to check the reproducibility of results. The average power $\left(P_{\mathrm{a}}\right)$ value was calculated using Equation (1), this was derived from the product of the measured instantaneous current $\left(I_{i}\right)$ and instantaneous voltage $\left(V_{i}\right)$ values.

$$
P_{\mathrm{a}}=\int_{0}^{T} I_{i}(t) V_{i}(t) \mathrm{d} t
$$

\section{Analytical heat transfer modelling}

The first method uses the analytical solution of heat equation initially proposed by Rosenthal [23]. This method gives an analytical temperature field that is compared to temperatures measured with thermocouples. This solution is obtained under few assumptions:

- First, the heat transfers by radiation and convection are neglected, considering the temperature change is only due to the heat-conduction governed by the 


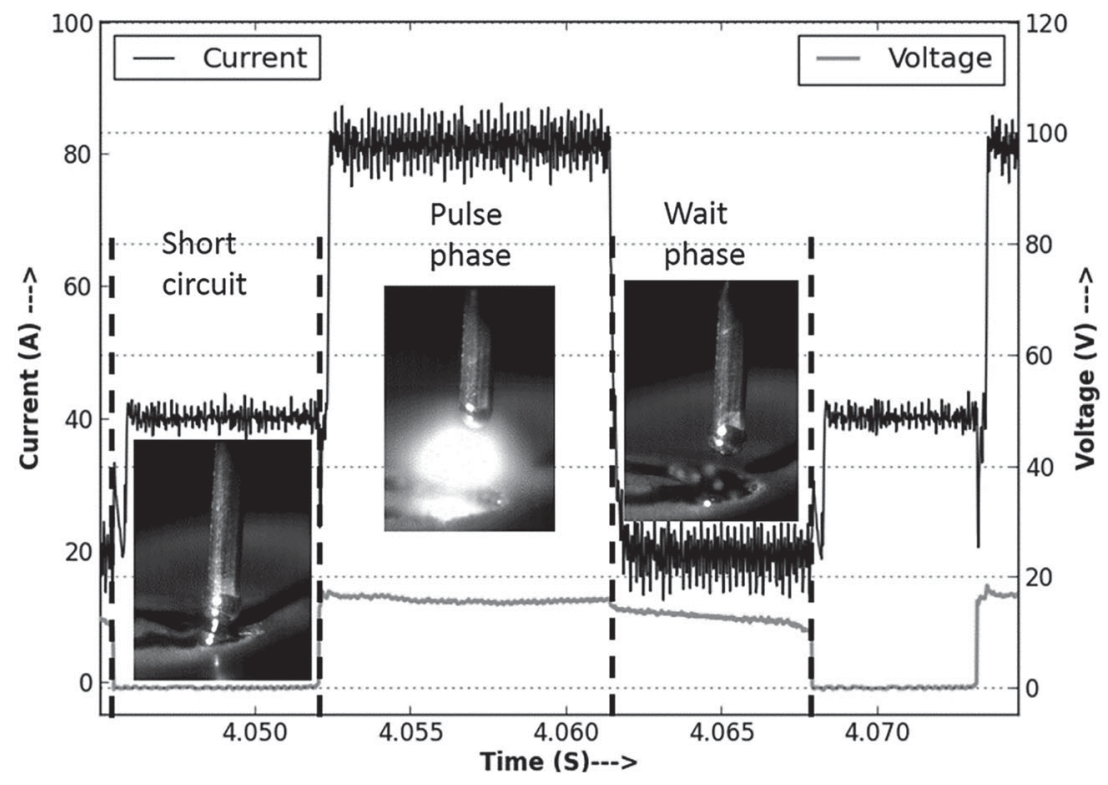

Figure 2. Current and voltage waveforms and metal transfer mechanism of the CMT process.

flowing transient heat transfer equation:

$$
\rho(T) c(T) \frac{\partial T}{\partial t}=Q+\operatorname{div}(\lambda(T) \cdot \operatorname{grad}(T))
$$

where $t$ is the time (s), $T$ is the temperature (K), $\rho$ is the density $\left(\mathrm{kg} \mathrm{m}^{-3}\right), c$ is the specific heat $\left(\mathrm{J} \mathrm{kg}^{-1} \mathrm{~K}^{-1}\right), \lambda$ is the thermal conductivity $\left(\mathrm{W} \mathrm{m}^{-1} \mathrm{~K}^{-1}\right)$ and $Q$ is an internal heat source $\left(\mathrm{W} \mathrm{m}^{-3}\right)$ supposed equal to zero.

- Second, the physical properties $\rho, c$ and $\lambda$ of the material are assumed to be independent of the temperature.

- Third, the heat source is assumed punctual and moves at a constant velocity $v$. An Eulerian coordinate system centred (Figure 3 ) on the heat source is defined as

$$
X=x-v t .
$$

- Fourth, the thermal field is assumed to be quasistationary, i.e. stationary in the Eulerian coordinates system.

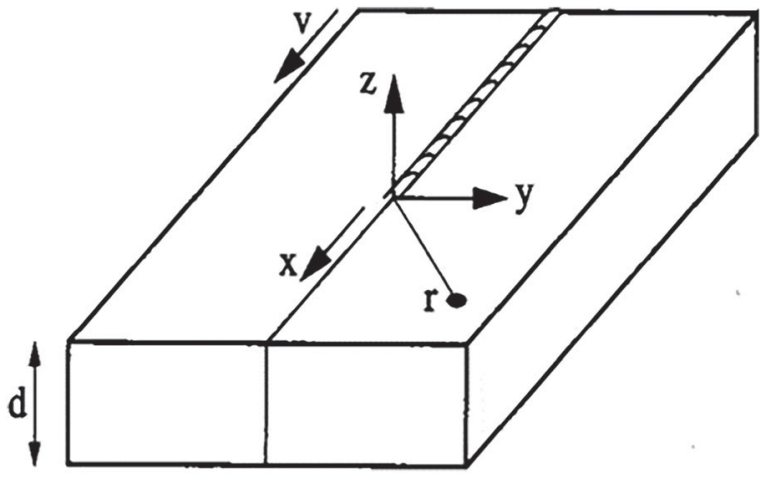

Figure 3. Coordinate definition of a heat source moving at constant speed $v$.
In the case of welding of thin products, the heat flow can be neglected in the thickness direction. Poorhaydari et al. [24] proposed a solution of Equation (2) as follows:

$$
T=T_{0}+\frac{q / v}{d(4 \pi \lambda \rho c t)^{1 / 2}} \exp \left(\frac{-r^{2}}{4 K . t}\right)
$$

where $r(\mathrm{~m})$ is the distance from the heat source, $d$ is (m) the plate thickness, $q\left(\mathrm{~J} \mathrm{~s}^{-1}\right)$ is the effective power of the heat source and $\mathrm{K}\left(\mathrm{m}^{2} \mathrm{~s}^{-1}\right)$ is the thermal diffusivity.

The effective power $q$ is defined as the electric power generated by the arc according to the relation $q=\eta \mathrm{VI}$ with $\eta$ the process efficiency, $V(\mathrm{~V})$ the voltage and $I(\mathrm{~A})$ the intensity of the electric arc.

Furthermore, the solution of Equation (3) allows determining the cooling time between temperature $T_{1}$ and temperature $T_{2}$.

$$
\Delta t_{T_{2}}^{T_{1}}=\frac{(q / v d)^{2}}{4 \pi \lambda \rho C\left(1 /\left(T_{2}-T_{0}\right)^{2}-1 /\left(T_{1}-T_{0}\right)^{2}\right)}
$$

\section{Numerical heat transfer modelling}

The second proposed method is an original approach to quantify the CMT process efficiency. It has a numerical heat transfer simulation using the information provided with thermocouples and the IMC layer thickness distribution at the $\mathrm{Al} /$ steel interface to calibrate the parameters of the heat source model and especially the process efficiency.

The numerical heat transfer simulation is carried out in two steps. In the first step, the thermal problem is solved with the finite element free software Elmer. It gives the temperature field in the whole plate. In the second step, the thermal cycles at each node of the steel/aluminium interface are extracted to compute 
the thickness of the reaction layer, using a diffusional growth model.

\section{Studied geometry}

To reduce the calculation time, only a half of the plate is modelled $(250 \mathrm{~mm} \times 50 \mathrm{~mm} \times 1 \mathrm{~mm})$ since the geometry of the deposited aluminium bead is quasisymmetrical to the central vertical plane of the steel sample (Figure 3). The aluminium deposit is not modelled (weld bead). The heat generated by the electric arc is modelled as a surface heat source. The plate is meshed with GMSH software with 3D elements (tetrahedra of first order). The mesh is refined in the zone below and near the heat source in order to get an accurate temperature field and thermal gradient. As well as a great number of nodes are required in order to calculate the thickness distribution of the IMC layer.

\section{Boundary conditions}

In order to solve numercially the heat Equation (2), it is required to define the boundary conditions applied on the outer surfaces (Figure 5). The arc heating is modelled as a surface heat flux distribution depending on welding power. This distribution is modelled in the Eulerian system with a double Gaussian distribution Equation (5) as Figure 4 shows. A different Gaussian radius is used along $X$ and $Y$ axis. Furthermore, a different Gaussian radius is used if the heat flux is at the front of the welding torch or at the back, as depicted in Figure 3. Goldak et al. [25] proposed this modelling taking into account artificially the flow of the molten metal at the back of the weld pool as well as the release of latent heat during the solidification.

$$
q(x, y, z)=q_{0} \exp \left(-\frac{3 x^{2}}{a_{\zeta}}\right) \exp \left(-\frac{3 y^{2}}{b^{2}}\right)
$$

the subscript $\zeta$ takes either $f$ or $b$ depending on whether $x$ is in front of or behind the heat source centre (or welding torch centre). So, $a_{\mathrm{f}}$ is the front half-length of the distribution $(\mathrm{m}), a_{\mathrm{b}}$ is the rear half-length $(\mathrm{m}), b$ is the half-width (m), and $q_{0}$ is the power surface density $\left(\mathrm{W} \mathrm{m}^{-2}\right)$ at Gaussian centre.

The parameters of the heat source model can be deduced from the welding power by integrating the distribution Equation (5) in the plane of the sample surface, assumed to be infinite compared to the size of the heat source:

$$
\begin{array}{r}
\int_{-\infty}^{+\infty} \int_{-\infty}^{+\infty} q_{0} \exp \left(-\frac{3 x^{2}}{a_{\zeta}}\right) \\
\exp \left(-\frac{3 y^{2}}{b^{2}}\right) \mathrm{d} x \mathrm{~d} y=\eta V I
\end{array}
$$

which gives

$$
q_{0}=\frac{12 \eta V I}{\pi b\left(a_{f}+a_{b}\right)}
$$

The half-width value $b$ is taken equal to the halfwidth of the deposited aluminium bead for each test. The front half-length $\left(a_{\mathrm{f}}\right)$ and the rear half-length $\left(a_{\mathrm{b}}\right)$ are identified with the method proposed by Kerrouault [26]. This method consists in measuring these two parameters from the size of the crater formed at the arc extinction due to the rapid solidification of the aluminium. The value of the heat efficiency $\eta$ remains the only unknown parameter to be determined by comparing simulation to experimental results.

The plate surfaces are also subjected to heat exchange with its surroundings during the welding operation, as shown in Figure 5. The plate cooling is due to convection, radiation and heat conduction through the whole plate. As the steel plate is clamped to the support with four punctual points at its corners, the thermal losses by conduction in the support are neglected. A homogenous Neuman condition $\partial T / \partial y=0$ is applied on the

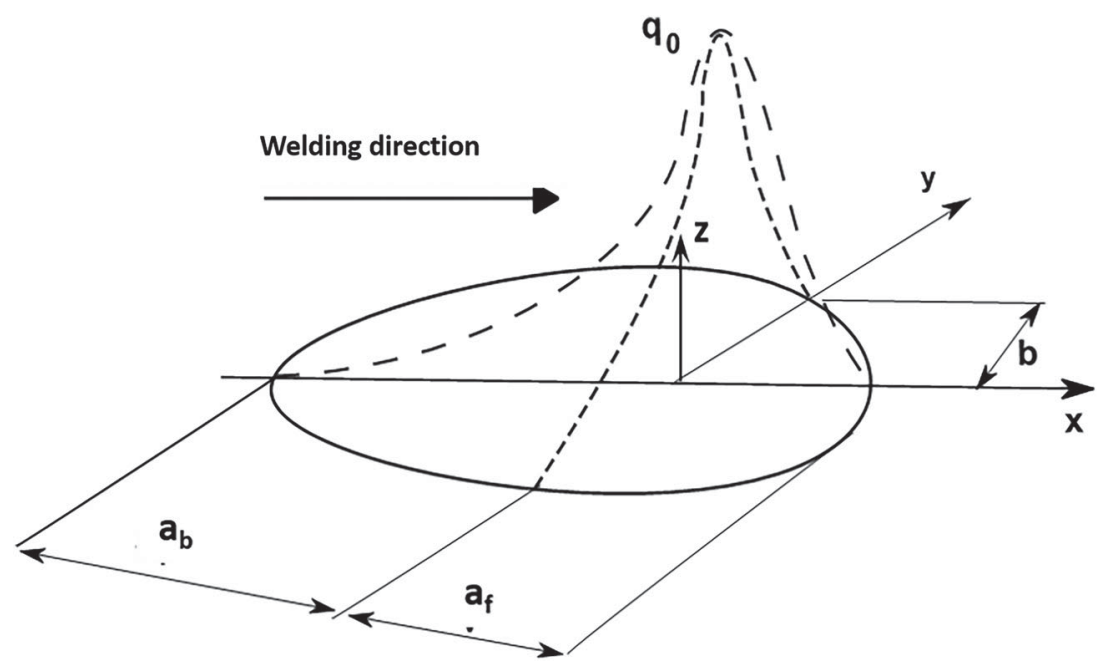

Figure 4. Schematic representation of the power distribution of the double Gaussian model. 


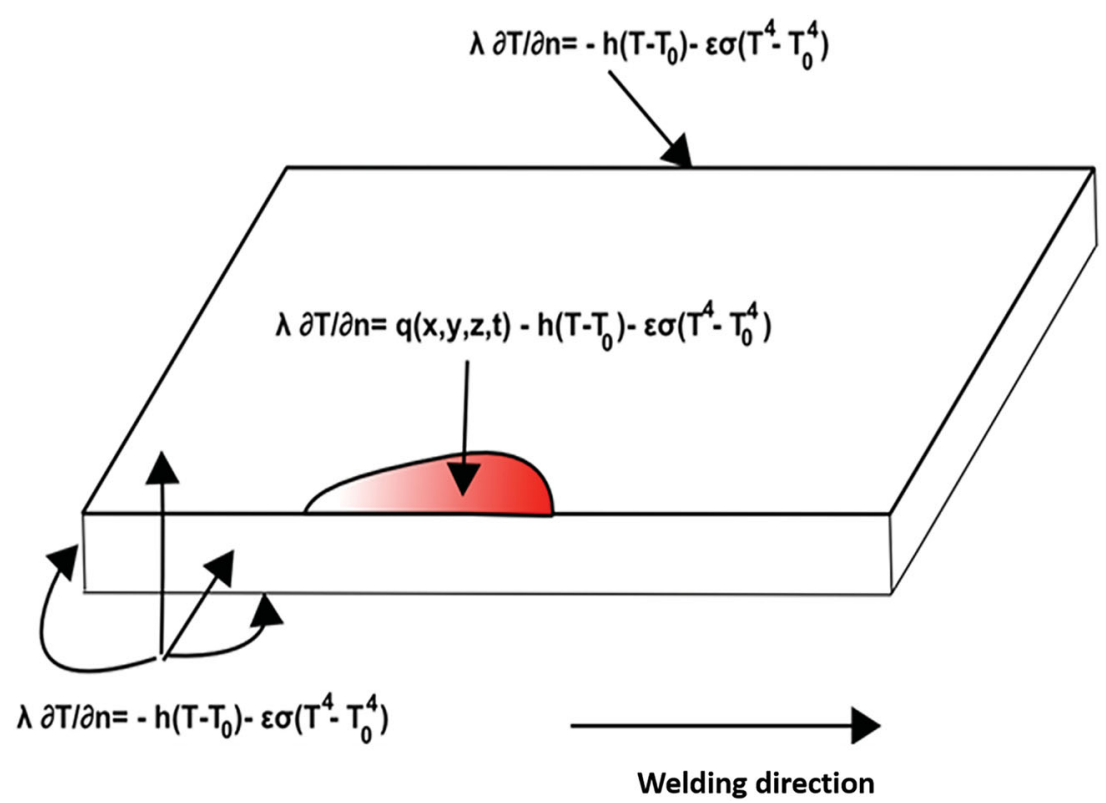

Figure 5. Applied boundary conditions.

$y=0$ plane to take into account the symmetry of the sample. The heat losses on the other surfaces due to the convection and radiation are given by

$$
\begin{gathered}
q_{c}=h\left(T-T_{0}\right) \\
q_{r}=\varepsilon \sigma\left(T^{4}-T_{0}^{4}\right)
\end{gathered}
$$

where $h=15\left(\mathrm{~W} \mathrm{~m}^{-2)}\right.$ is the convection coefficient, $\varepsilon=0.6$ is the emissivity, $\sigma=5.6710^{-8}\left(\mathrm{~W} \mathrm{~m}^{-2} \mathrm{~K}^{-4}\right)$ is the Boltzmann constant and $T_{0}=295 \mathrm{~K}$ is the room temperature.

\section{Material thermo-physical properties}

The thermal conductivity $\lambda$ and the specific heat $\mathrm{C}$ are considered as temperature dependent within the range $[300-1000 \mathrm{~K}]$. The values used in the simulation are those proposed by Theodore et al. [27] for a low-carbon steel (Table 2). The density of the steel $\rho$ is considered independent of the temperature and equal to $7854 \mathrm{~kg} \mathrm{~m}^{-3}$. The latent heat of fusion is not taken into account, because it has not a great influence on the thermal calculation, as proved by Sierra [28].

\section{Growth modelling of the IMC layer}

Mezrag et al. [29] determined that the intermetallic layer formed in all the welded experiments is predominantly composed of the $\mathrm{Fe}_{2} \mathrm{Al}_{5}$ phase containing a

Table 2. Thermo-physical properties of low carbon steel [27].

\begin{tabular}{lccccc}
\hline$T(\mathrm{~K})$ & 300 & 400 & 600 & 800 & 1000 \\
\hline$C\left(\mathrm{~J} \mathrm{~kg}^{-1} \mathrm{~K}^{-1}\right)$ & 434 & 487 & 559 & 685 & 1169 \\
$\lambda\left(\mathrm{W} \mathrm{m}^{-1} \mathrm{~K}^{-1}\right)$ & 60.5 & 56.7 & 48.0 & 39.2 & 30.0 \\
\hline
\end{tabular}

relatively high Si content. According to the results of Shahverdi et al. [30] and Dong et al. [31], it was assumed that the growth of the reaction layer is governed by the diffusion of $\mathrm{Fe}$ and $\mathrm{Al}$ through this layer. Under isothermal conditions, the diffusion-controlled growth can be modelled with a parabolic law:

$$
n=\left(2 K_{T} t\right)^{1 / 2}
$$

where $n$ is the thickness of the IMC layer $(\mathrm{m}), K_{T}$ is the growth kinetic constant at temperature $T\left(\mathrm{~m}^{2} \mathrm{~s}^{-1}\right)$ and $t$ is the interaction time (s).

The constant $K_{T}$ varies as a function of the temperature according to an Arrhenius law:

$$
K_{T}=K_{0} \exp \left(-\frac{Q}{R T}\right)
$$

where $K_{0}$ is the frequency factor $\left(\mathrm{m}^{2} \mathrm{~s}^{-1}\right), Q$ is the activation energy $\left(\mathrm{J} \mathrm{mol}^{-1}\right), R$ is the gas constant $\left(R=8.314 \mathrm{~J} \mathrm{~mol}^{-1} \mathrm{~K}^{-1}\right)$, and $T$ is the temperature $(\mathrm{K})$.

Under non-isothermal conditions, it may be assu med that the thickness of IMC layer is equal to the sum of the thicknesses $d n$ formed at each temperature of the thermal cycle, decomposed into isothermal steps of duration $d t$ :

$$
d n=\left(\frac{K_{0}}{2}\right)^{1 / 2} \exp \left(-\frac{Q}{2 R T}\right) t^{-1 / 2} \mathrm{~d} t
$$

By discretising the thermal cycle in isothermal steps of duration $\Delta t$, the final thickness is given by

$$
n=\sum_{t_{i}}^{t_{f}}\left(\frac{K_{0}}{2}\right)^{1 / 2} \exp \left(-\frac{Q}{2 R T}\right) t^{-1 / 2} \Delta t
$$


where $t_{i}$ and $t_{f}$, are, respectively the beginning time and the end time of the interaction between aluminium and steel.

We assume that the interaction begins (time $t_{i}$ ) when the steel surface reaches $600^{\circ} \mathrm{C}$, a value chosen within the melting range of the deposited $\mathrm{Al}-5 \mathrm{Si}$ metal (between 573 and $625^{\circ} \mathrm{C}$ ). The values for the activation energy and frequency factor values were determined by Yin et al. [32] who immersed pure iron (99.99\%) in an aluminium alloy bath containing $3 \%$ silicon, a composition close to the alloy used in this study, between 700 and $850^{\circ} \mathrm{C}$ so $Q=172 \mathrm{~kJ} \mathrm{~mol}^{-1}$ and $k_{0}=0.69$ $10^{-3} \mathrm{~m}^{2} \mathrm{~s}^{-1}$.

\section{Results}

\section{Temperature measurements}

Figure 6 shows the temperature measurements reco rded by the thermocouples for the two tests No. 2 . Temperature reaches its maximum $\left(700^{\circ} \mathrm{C}\right)$ in the measurement point with a high velocity $\left(350^{\circ} \mathrm{s}^{-1}\right)$. During the cooling phase from 600 to $500^{\circ} \mathrm{C}$, some oscillations appeared on the temperature measurement. These oscillations could be related to changes in the contact surface between the thermocouple and the workpiece due to dilatation/shrinkage effect. Therefore, it induced errors in the measured temperatures. However, these oscillations disappeared below $500^{\circ} \mathrm{C}$. All the data below this value are considered for the estimation of process efficiency. It can be seen that the two thermocouples of the same specimen provide substantially the same thermal cycles, which indicates a quasi-stationary thermal transfer mode. One thermocouple of test 2 reached lower values than the three others (thermocouple 1 of test 2 for instance). It can be due to a bad thermal contact or a bad positioning in the drilled hole. As a consequence, this measure is not taken into account in what follows.

\section{Intermetallic thicknesses}

The distribution of the IMC layer thickness at the steel/aluminium interface is shown in Figure 7. It varies according to the process parameters and its distribution follows that of the heat input one which it is maximal in the centre and decreases to zero near the edges of the aluminium deposit. The measured thicknesses show some dispersions due to the irregular aspect of the IMC layer on the aluminium side, having a 'tonguelike' shape (Figure 8). In order to facilitate the comparison with the computed thickness values, the measured thickness values are interpolated using a polynomial function in order to obtain a regular thickness distribution.

Table 3 resumes the maximal thickness and the width of the reaction layers measured for all the tests.

\section{Process efficiencies identified from the analytical model}

The heat efficiency is estimated with the first method using Equation (4) giving the theoretical cooling time between two temperatures in the heat source centre. The thermocouples were positioned at only $0.2 \mathrm{~mm}$ of the centre of the $\mathrm{Al}$ deposit, it was considered that the measured cooling cycle is similar to the one at the heat-source centre. The experimental curves giving thermal cycles for the various tests were sometimes disturbed above $500^{\circ} \mathrm{C}$, so only the temperatures in the range $500-300^{\circ} \mathrm{C}$ were used to measure the cooling time. The material properties of the steel used

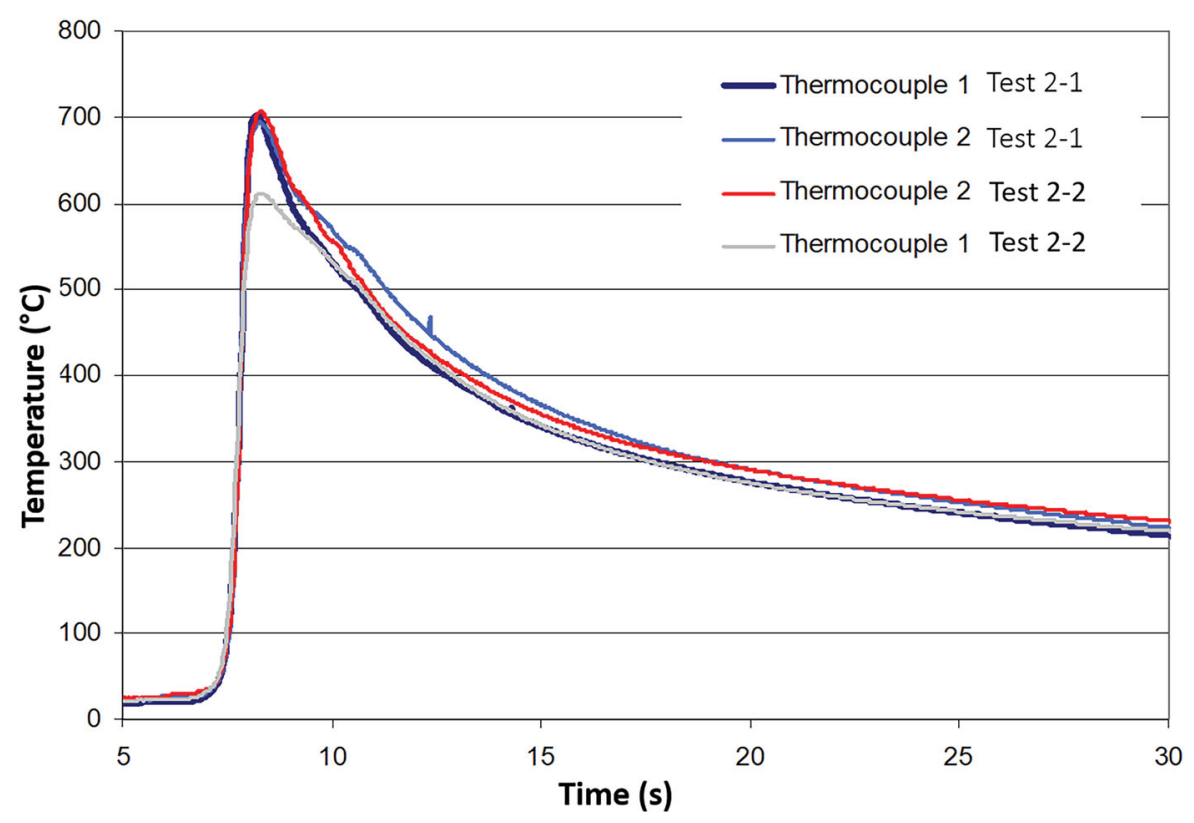

Figure 6. Comparison of temperature measurements for test No 2. 


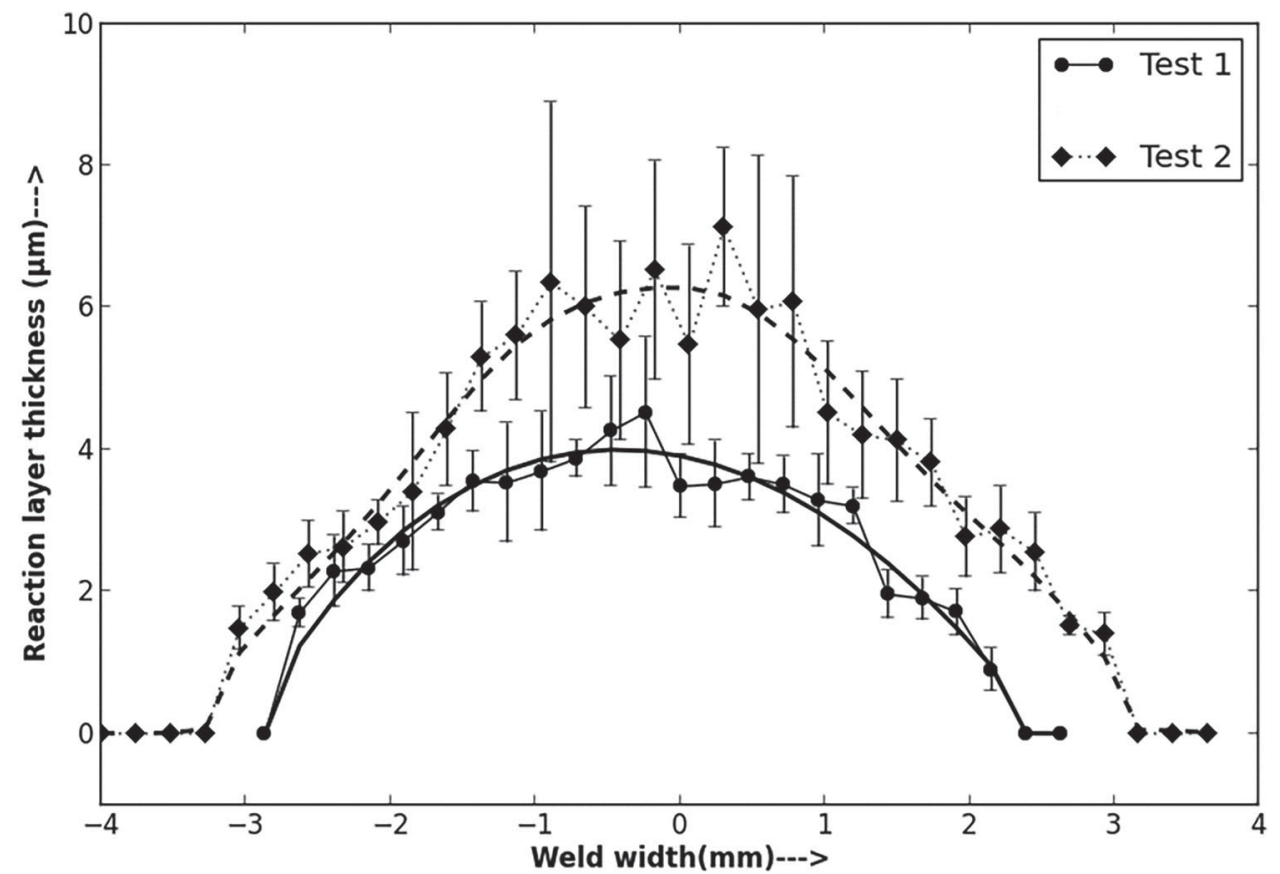

Figure 7. Thickness distribution of the IMC layers measured along the steel/aluminium interface.
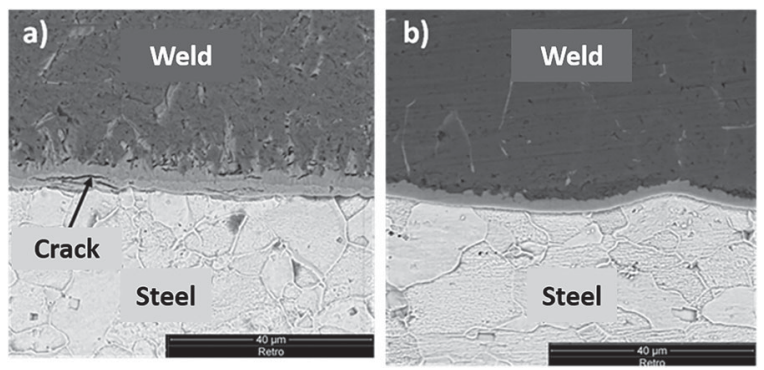

Figure 8. Micrographs of the intermetallic layer formed at the steel/aluminium interface for the tests No 4 and 5 .

Table 3. Maximal thickness and width of the IMC layer measured for the various tests.

\begin{tabular}{lccccccc}
\hline Test No & 1 & 2 & 3 & 4 & 5 & 6 & 7 \\
\hline Maximal thickness $(\mu \mathrm{m})$ & 4.1 & 6.3 & 5.4 & 6.2 & 3.9 & 3.2 & 6.3 \\
Width $(\mathrm{mm})$ & 4.4 & 6.2 & 8.6 & 10 & 6.4 & 6.2 & 8.4 \\
\hline
\end{tabular}

for the calculation are those given at room temperature in Table $2\left(\rho=7854 \mathrm{~kg} \mathrm{~m}^{-3}, C=434 \mathrm{~J} \mathrm{~kg}^{-1} \mathrm{~K}^{-1}\right.$, $\left.\lambda=60.5 \mathrm{~W} \mathrm{~m}^{-1} \mathrm{~K}^{-1}\right)$. Knowing the average electrical power and the welding speed for each test, the process efficiency can be deduced using Equation (4) (considering the cooling between 500 and $300^{\circ} \mathrm{C}$ measured from the experimental thermal cycles).

The results are summarised in Table 4. It may be noted that the fraction of the welding energy transferred through the bonding interface is higher for type 2 waveform, with an averaged value of 0.93 than type 1 waveform with an averaged value of 0.78 according to the analytical model.

Figure 9 shows that the theoretical cooling cycles obtained with these calculated efficiencies and the measured temperature cycles are very similar for the various
Table 4. Cooling times from 500 to $300^{\circ} \mathrm{C}$ measured on the thermograms and process efficiencies calculated using relation (3).

\begin{tabular}{lccc}
\hline Test No & Average power $\left(\mathrm{J} \mathrm{s}^{-1}\right)$ & $\Delta t 500 / 300(s)$ & $\eta$ \\
\hline 1 & 477 & 4.6 & 0.78 \\
2 & 570 & 7.5 & 0.83 \\
3 & 786 & 9.2 & 0.67 \\
4 & 755 & 13.1 & 0.83 \\
5 & 463 & 6.2 & 0.93 \\
6 & 505 & 6.7 & 0.89 \\
7 & 523 & 8.4 & 0.96 \\
\hline
\end{tabular}

tests. The maximum temperature, on the other hand, is very overestimated by the model, which is quite consistent because the modelling considers that all the energy is located on a punctual point.

The proposed analytical model is based on several simplifying assumptions and it gives only an approximate estimation of the temperature fields. The punctual modelling of the heat source, in particular, does not make possible to determine the maximum temperature reached at a point too close to the centre of the heat source, which limits comparison with the experiments. The second developed method in the following section is based on a numerical heat transfer simulation. This is more representative of the real welding experiment and it should give a more accurate estimation of the heat transferred to the steel plate.

\section{Process efficiencies identified from numerical modelling}

Figure 10 shows the temperature distribution at the surface of the steel sheet in the quasi-stationary mode for the welding energy corresponding to test 1 . It can 


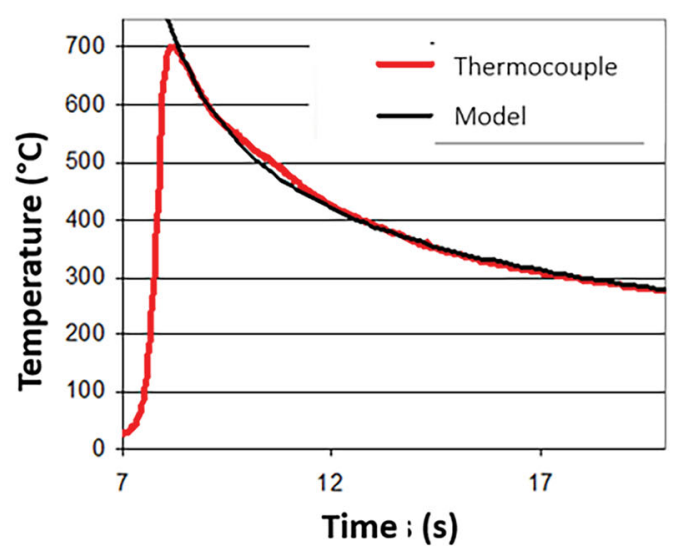

Test 2

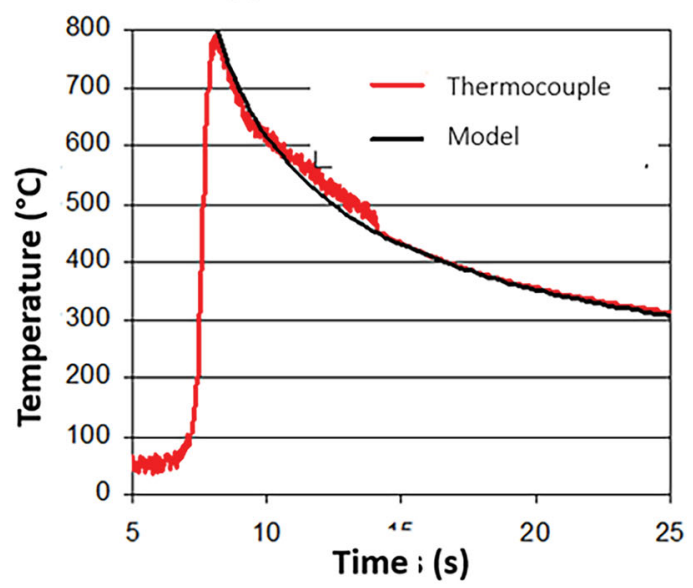

Test 4

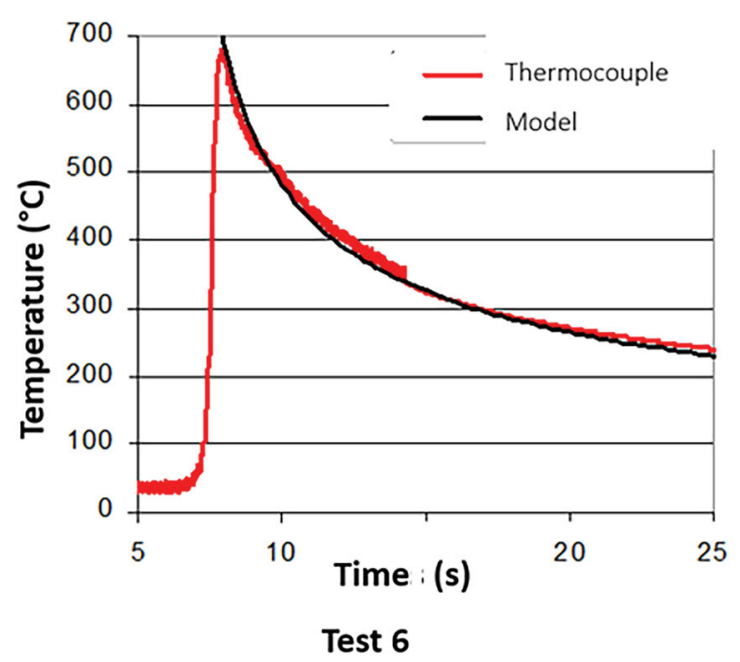

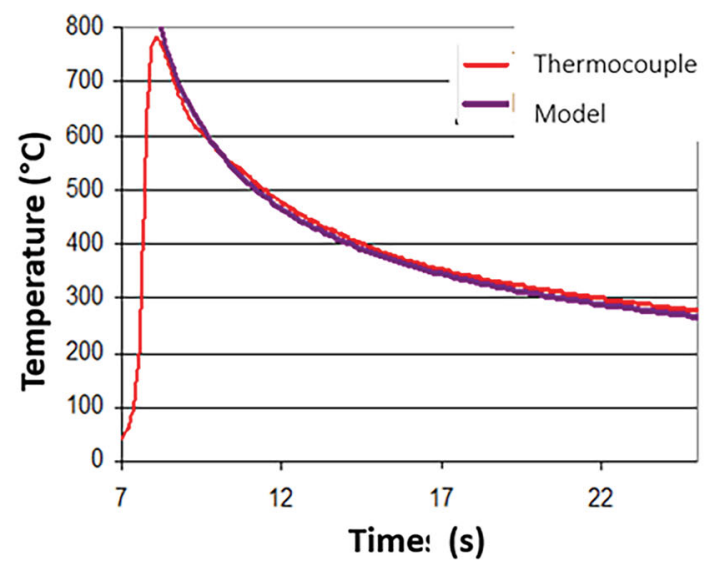

Test 3

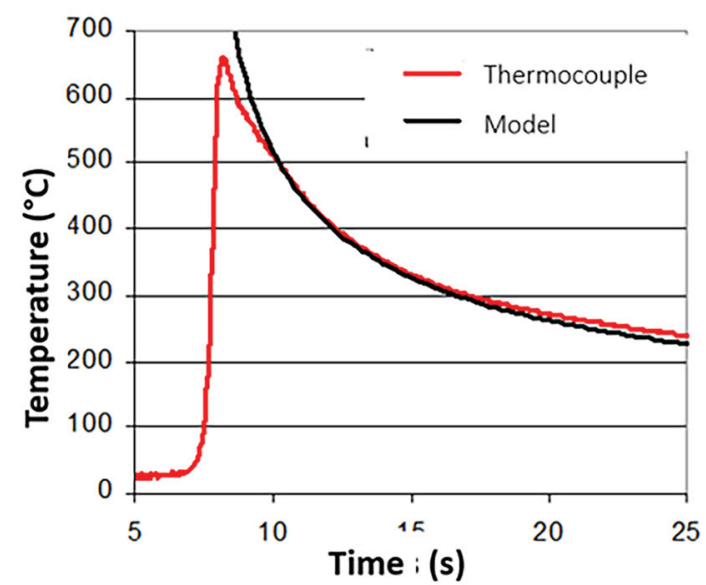

Test 5

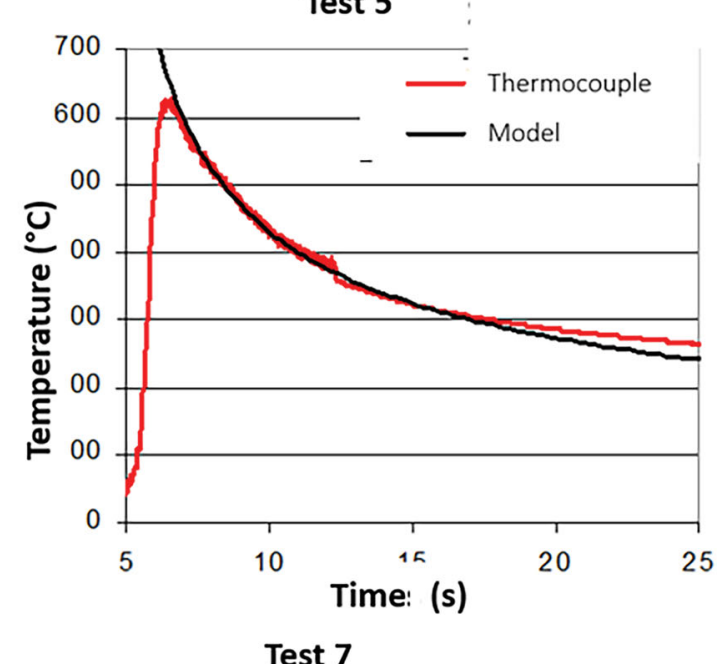

Test 7

Figure 9. Comparison of the cooling cycles measured and calculated using the analytical model.

be seen that the calculated temperatures reach locally more than $1273 \mathrm{~K}$. The temperature cycle at a node located in the quasi-stationary area, at the centre of the heat source, is exported in order to calculate the predicted maximal thickness of the IMC layer using Equation 12, with a time step of $0.1 \mathrm{~s}$.

The process efficiency is determined for each welding test by successive iterations until the maximum thickness and the width of the IMC layer were calculated by the model fit to the experimental results.
Figure 11 shows a good agreement between the measured and computed thickness distributions of the IMC layers after calibration of the efficiency for test 2. The comparison of the thermal cycle at the node located at $0.2 \mathrm{~mm}$ from the surface of the plate with that measured by thermocouple (Figure 12) also shows a good agreement, which seems to validate both the thermal modelling and the diffusional growth model of the IMC layer. Following the same approach, the heat source parameters, experimental and simulation of 


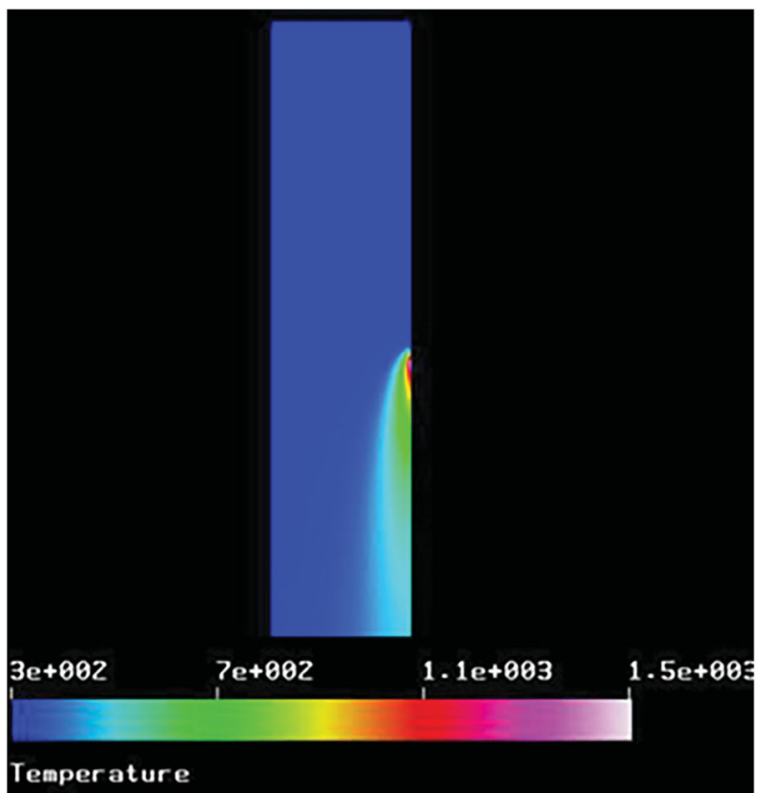

Figure 10. Temperature distribution $\left({ }^{\circ} \mathrm{K}\right)$ at the surface of the steel sheet of test 1 .

IMC dimensions (thickness, width) and the calibrated process efficiency for all tests are presented in Table 5.

The estimated process efficiencies are very close to those calculated with the analytical method. The general trend shows a decrease in process efficiency when the average power increases. In addition, there are significant differences between the two types of used current waveforms. The average value of the process efficiency is 0.78 for type 1 waveform and 0.92 for type 2 waveform. The main difference between these two waveform types is the duration of the 'pulse phase' (Figure 2) which is longer for type 1. During this phase, the filler wire tip is heated by the condensation heat of electrons crossing the arc before transferring the heat to the steel plate during the short-circuit phase. It is assumed that a longer pulse phase favours the heat losses by conduction from the filler wire tip towards the welding torch what decreases the process efficiency. It can be seen from Table 5 that the maximal IMC thicknesses of tests 1 and 5 are almost identical, with an obvious difference in their width, despite the fact that the test power 1 is larger than test power 5 . This supports our hypothesis of excess heat loss with the waveform type 1, which reduces the efficiency and so the heat input and consequently the maximal IMC thickness. Note also that the process efficiency determined for test 3, corresponding to the higher average power, is significantly lower than the ones determined for the other tests carried out with the same type 1 waveform. This low efficiency value could be attributed, in addition to heat loss, to the vaporisation of the zinc coating when the average power becomes too high. According to Zhou and Lin [33], the vaporisation of zinc consumes a part of the energy transferred to the steel plate which is not subsequently restored if the zinc does not condense at the same place on the plate.

\section{Conclusion}

Two indirect methods have been developed to estimate the process efficiency of the CMT welding process for various welding parameters corresponding to two types of current waveforms. Both methods were based on experimental tests consisting in depositing an $\mathrm{Al}_{-} \mathrm{Si}_{5}$ filler wire on a galvanised steel plate. Then the temperature cycle was measured as well as the thickness

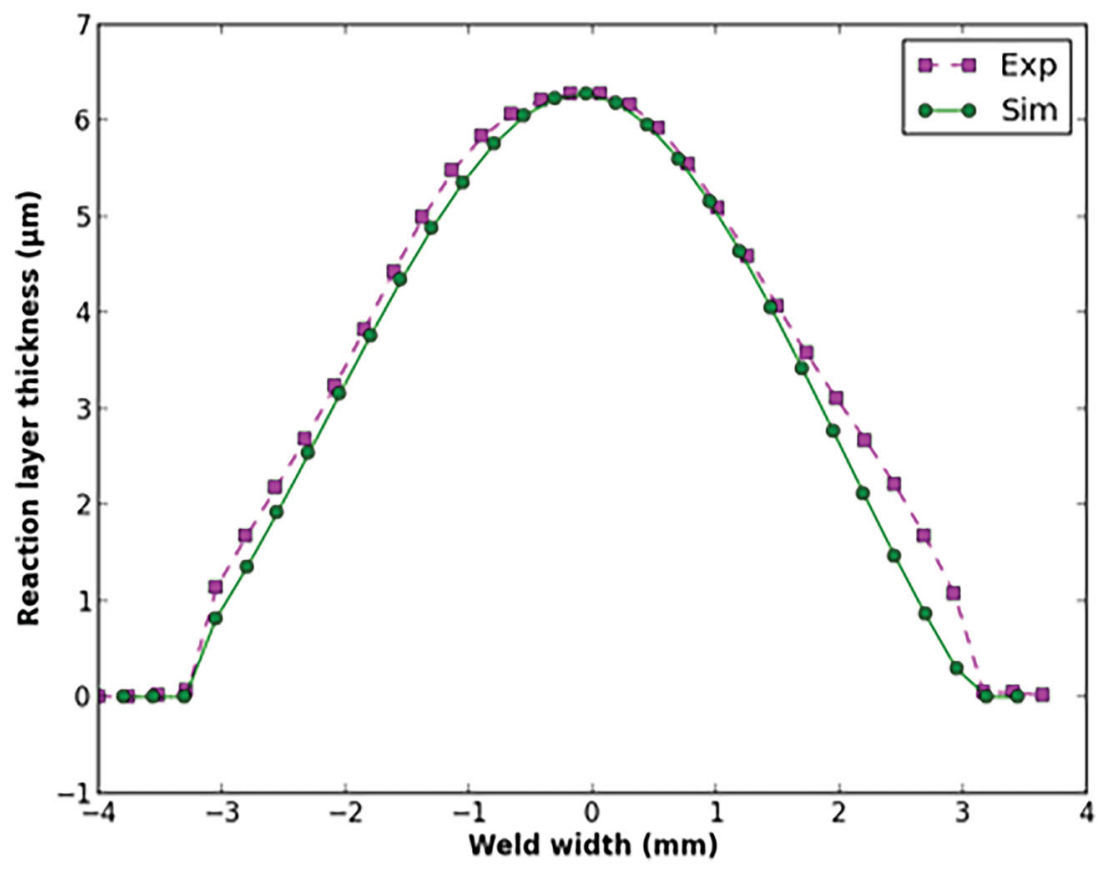

Figure 11. Comparison of experimental and calculated thickness distributions of the IMC layer for test 2. 


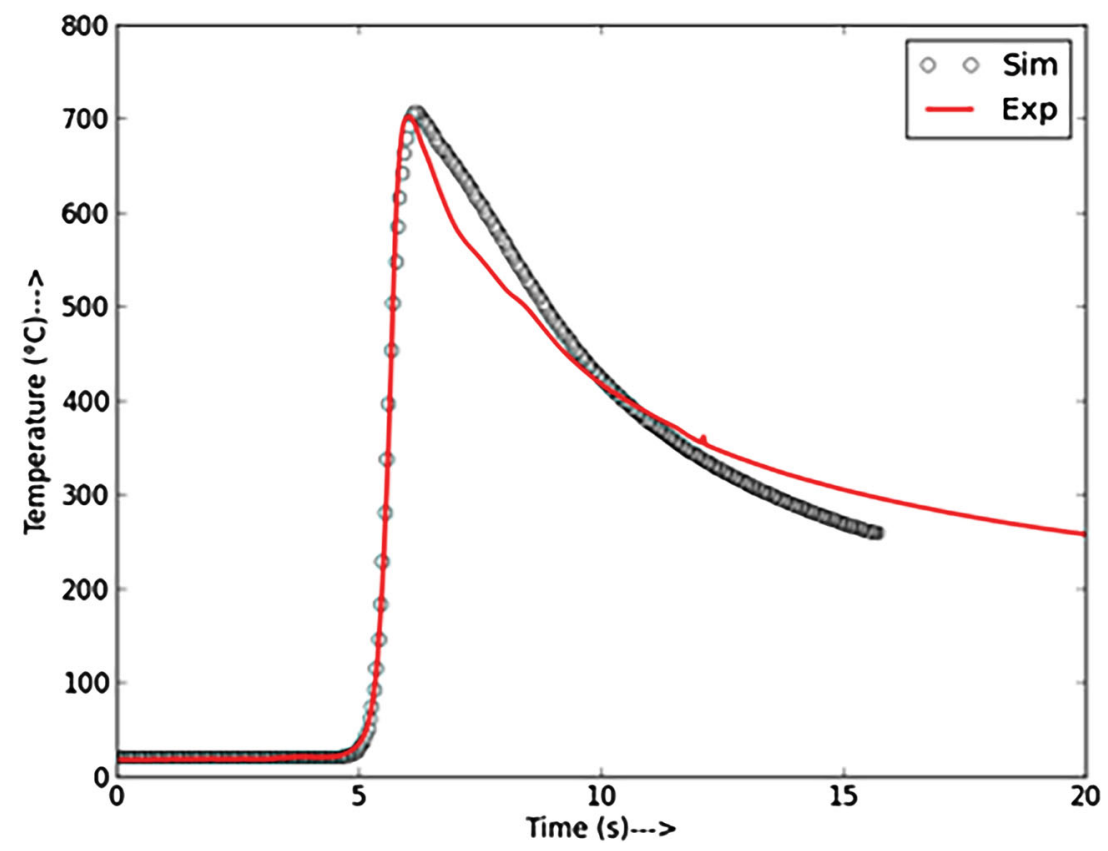

Figure 12. Comparison of experimental and simulated thermal cycles of test 2 .

Table 5. Heat source parameters used to model the welding tests and deduced process efficiencies.

\begin{tabular}{lccccccccc}
\hline Test & $\begin{array}{c}\text { Average } \\
\text { power } \\
\text { No }\end{array}$ & $\begin{array}{c}b \\
\left(\mathrm{~J} \mathrm{~s}^{-1}\right)\end{array}$ & $\begin{array}{c}a_{\mathrm{f}} \\
(\mathrm{mm})\end{array}$ & $\begin{array}{c}a_{\mathrm{b}} \\
(\mathrm{mm})\end{array}$ & $\begin{array}{c}\mathrm{Th}_{\operatorname{Exp}} \\
(\mu \mathrm{mm})\end{array}$ & $\begin{array}{c}\mathrm{Th}_{\text {sim }} \\
(\mu \mathrm{m})\end{array}$ & $\begin{array}{c}W_{\operatorname{Exp}} \\
(\mathrm{mm})\end{array}$ & $\begin{array}{c}W_{\text {sim }} \\
(\mathrm{mm})\end{array}$ & $\eta$ \\
\hline 1 & 477 & 2.8 & 2.53 & 6 & 4.1 & 4 & 4.4 & 4.6 & 0.80 \\
2 & 570 & 4.2 & 3.75 & 7.2 & 6.3 & 6.1 & 6.2 & 6 & 0.85 \\
3 & 786 & 5.6 & 4.45 & 7.3 & 5.4 & 5.3 & 8.6 & 8.2 & 0.67 \\
4 & 755 & 6.7 & 5.2 & 7.68 & 6.2 & 6.1 & 10 & 9.8 & 0.79 \\
5 & 463 & 4.3 & 3.43 & 6.24 & 3.9 & 4 & 6.4 & 7.2 & 0.93 \\
6 & 505 & 4.78 & 4.2 & 6.66 & 3.2 & 3.2 & 6.2 & 6.4 & 0.89 \\
7 & 523 & 4.9 & 3.6 & 5.8 & 6.3 & 6.2 & 8.2 & 8.4 & 0.96 \\
\hline
\end{tabular}

distribution of the $\mathrm{Fe}-\mathrm{Al}$ intermetallic formed at the steel/Al interface.

The first method is based on the calculation of the process efficiency using an analytical model and cooling rates estimated from thermocouple measurements. The second method is based on a two-step numerical heat transfer model of the welding operation. First, a thermal simulation is carried out to predict the thermal cycle at the steel/aluminium interface. Second, a diffusional-growth model is used to predict the thickness of the formed intermetallic layer. The process efficiency is deduced after calibrating of the heat source in order to match the simulated intermetallic thickness with the measured one.

The estimated process efficiencies from the two methods are very close, but the numerical simulation is more representative of reality. The results revealed that the process efficiency is higher for current waveforms with very short pulses, with an average efficiency of 0.92 , than the one with longer current pulses where the efficiency decreased to 0.78 . An excessive decrease in the process efficiency with the increase in average welding power is observed, maybe due to the vaporisation of the zinc coating, which absorbed a fraction of the energy generated by the electric arc. In our study case, the numerical simulation approach has proved its accuracy to estimate the studied process efficiency.

\section{Disclosure statement}

No potential conflict of interest was reported by the authors.

\section{Funding}

The financial support was given by Erasmus Mundus program for this study.

\section{ORCID}

Sebastien Rouquette (D) http://orcid.org/0000-0002-18496142

Mustapha Benachour (D) http://orcid.org/0000-0002-8415241X

\section{References}

[1] David SA, Vitek JM. Correlation between solidification parameters and weld microstructures. Int Mater Rev. 1989;34(5):213-245.

[2] Liu S, Mi G, Yan F, et al. Correlation of high power laser welding parameters with real weld geometry and microstructure. Opt Laser Technol. 2017;94(9):59-67.

[3] Radaj D. Heat effects of welding. Berlin: SpringerVerlag; 1992.

[4] DuPont JN, Marder AR. Thermal efficiency of arc welding processes. Weld J Res Suppl. 1995;74:406s-416s.

[5] Niles RW, Jackson CE. Weld thermal efficiency of the GTAW process. Weld J. 1975;54(1):26s-32s.

[6] Orlowicz AW, Trytek A. Susceptibility of iron castings to heat absorption from an electric arc and to hardened-layer shaping. Metall Mater Trans A. 2003;34(12):2973-2984. 
[7] Collings N, Wong KY, Guile AE. Efficiency of tungsteninert-gas arcs in very-high-speed welding. Inst Electr Eng. 1979;126(3):276-280.

[8] Giedt WH, Tallerico LN, Fuerschbach PW. GTA welding efficiency: calorimetric and temperature field measurement. Weld J. 1989;68:28s-32s.

[9] Stenbacka N, Choquet I, Hurtig K. Review of arc efficiency values for gas tungsten arc welding. IIW Commission IV-XII-SG212; 2012 Apr 18-20; Berlin, Germany. p. 1-21.

[10] Lesnewich A. Control of melting rate and metal transfer in gas shielded metal arc welding. Part i - control of electrode melting rate. Weld J. 1958;37:418-425.

[11] Waszink JP, Van Den Heuvel M. Heat generation and heat flow in the filler metal in GMA welding. Weld J. 1982;61:269-280.

[12] Bosworth MR. Effective heat input in pulsed gas metal arc welding with solid wire electrodes. Weld J. 1991;70:111s-117s.

[13] Joseph A, Harwig D, Farson DF, et al. Measurement and calculation of arc power and heat transfer efficiency in pulsed gas metal arc welding. Sci Technol Weld Join. 2003;8(6):400-406.

[14] Pickin CG, Williams SW, Lunt M. Characterisation of the cold metal transfer (CMT) process and its application for low dilution cladding. J Mater Process Technol. 2011;211(3):496-502.

[15] Mezrag B, Deschaux-Beaume F, Benachour M. Control of mass and heat transfer for steel/aluminum joining using cold metal transfer process. Sci Technol Weld Join. 2015;20(3):189-198.

[16] Pépe N, Egerland S, Colegrove P, et al. Measuring the process efficiency of controlled gas metal arc welding processes. Sci Technol Weld Join. 2011;16(5):412-417.

[17] Egerland S, Colegrove P. Arc welding: using solid state calorimetry for measuring gas metal arc welding efficiency. Rijeka: Intech; 2011.

[18] Malin V, Sciammarella F. Controlling heat input by measuring net power. Weld J. 2006;85:44-50.

[19] Colegrove P, Ikeagu C, Thistlethwaite A, et al. The welding process impact on residual stress and distortion. Sci Technol Weld Join. 2009;14(8):717-725.

[20] Cao R, Yu G, Chen JH, et al. Cold metal transfer joining aluminum alloys-to-galvanized mild steel. J Mater Process Technol. 2013;213(10):1753-1763.
[21] Lin J, Ma N, Lei Y, et al. Shear strength of CMT brazed lap joints between aluminum and zinc-coated steel. J Mater Process Technol. 2013;213(8):1303-1310.

[22] Peyre P, Sierra G, Deschaux-Beaume F, et al. Generation of aluminium-steel joints with laser-induced reactive wetting. Mater Sci Eng A. 2007;444(1-2): 327-338.

[23] Rosenthal D. Mathematical theory of heat distribution during welding and cutting. Weld J. 1941;5: 220-234.

[24] Poorhaydari K, Patchett BM, Ivey D. Estimation of cooling rate in the welding of plates with intermediate thickness. Suppl Weld J. 2005;84(10):149s-155s.

[25] Goldak J, Chakravarti A, Bibby M. A new finite element model for welding heat sources. Metall Trans B. 1983;15B(2):299-305.

[26] Kerrouault N. Fissuration à chaud en soudage d'un acier inoxydable austénitique stabilisé au titane. Paris: Ecole Central Paris; 2000.

[27] Theodore L, Adrienne B, Lavine S, et al. Fundamentals of heat and mass transfer. John Wiley and Sons; 2002.

[28] Sierra G. Etude métallurgique et mécanique de l'assem blage hétérogène Acier/Aluminium par les procédé laser et TIG. Montpellier: Université de Montpellier II; 2006.

[29] Mezrag B. Etude de l'influence des paramètres de soudage sur la microstructure et le comportement mécanique des assemblages acier-aluminium obtenus par soudage MIG-CMT. Montpellier: Université de Montpellier; 2015.

[30] Shahverdi HR, Ghomashchi MR, Shabestari S, et al. Microstructural analysis of interfacial reaction between molten aluminum and solid iron. J Mater Process Technol. 2002;124(3):345-352.

[31] Dong H, Hu W, Duan Y, et al. Dissimilar metal joining of aluminum alloy to galvanized steel with $\mathrm{Al}-\mathrm{Si}$, $\mathrm{Al}-\mathrm{Cu}, \mathrm{Al}-\mathrm{Si}-\mathrm{Cu}$ and $\mathrm{Zn}-\mathrm{Al}$ filler wires. J Mater Process Technol. 2012;212(2):458-464.

[32] Yin F, Zhao M, Liu Y, et al. Effect of Si on growth kinetics of intermetallic compounds during reaction between solid iron and molten aluminum. Trans Nonferr Metal Soc China. 2013;23(2):556-561.

[33] Zhou Y, Lin Q. Wetting of galvanized steel by Al 4043 alloys in the first cycle of CMT process. J Alloys Compd. 2014;589(15):307-313. 